\title{
НОВЫЙ ПОДХОД К ИССЛЕДОВАНИЮ ЗДОРОВЬЕСБЕРЕГАЮЩЕЙ ДЕЯТЕЛЬНОСТИ ЛИЧНОСТИ
}

\author{
(C) Карпов А.В. ${ }^{1}$, Яковлева Н.В. ${ }^{2}$ \\ ${ }^{1}$ Ярославский государственный университет имени П.Г. Демидова, Ярославль; \\ ${ }^{2}$ Рязанский государственный медицинский университет имени академика И.П. Павлова, Рязань \\ E-mail: anvikar56@yandex.ru
}

\begin{abstract}
В статье рассматриваются перспективы использования теоретического конструкта витальной метакомпетентности личности в психологических исследованиях здоровья. В концепции данной работы витальная метакомпетентность личности рассматривается как активная и целенаправленная реализации субъектом своих витальных компетенций в социально-психологическом пространстве личности. Системными единицами витальной метакомпетентности выступают витальные компетенции, представляющие собой способности эффективно осваивать проблемные ситуации, связанные с угрозой здоровью, в социально-психологическом пространстве личности. Свойства витальной метакомпетентности на общесистемном уровне выступают в качестве критериев ее уровня сформированности, который в свою очередь задает устойчивость результатов лечения, а, следовательно, фон общей жизненной реализации личности.
\end{abstract}

Ключевые слова: здоровьесберегающая деятельность личности, компетентность, витальные компетенции.

\section{NEW APPROACH TO THE STUDY OF PERSON'S HEALTH ACTIVITIES}

Karpov A.V. ${ }^{l}$, Yakovleva N.V. ${ }^{2}$

${ }^{1}$ P.G. Demidov Yaroslavl State University, Yaroslavl; ${ }^{2}$ Ryazan State Medical University, Ryazan

This article discusses the prospects of using the theoretical construct of person's vital metacompetence in mental health research. In this work the concept of person's vital metacompetence is considered as an active and purposeful implementation of person's vital metacompetence in social and psychological space of an individual. System units of vital metacompetence involve vital competence as the ability to cope effectively with problematic situations related to health hazards in social and psychological space of an individual. Systemic properties of vital metacompetence act as criteria for the level of its formation which, in turn, determines the stability of treatment results and, therefore the overall pattern of the individual life realization.

Keywords: person's health activities, competence system, vital competence.

Анализ современных исследований в области психологии здоровья обнаруживает серьезную проблему рассогласования актуальности решаемых задач и возможностей используемой методологической парадигмы. Психология здоровья чаще всего представлена эмпирическими исследованиями, решающими узкие прикладные задачи без должного теоретического обобщения. Для разработки современной психологической теории здоровья, доступной для операционализации в прикладных исследованиях, целесообразно, на наш взгляд, придерживаться следующих рекомендаций:

1. Рассматривать психологическую систему здоровья в контексте общей жизнедеятельности человека и изучать ее в общепсихологическом и социально-психологическом дискурсе как личностную активность в области здоровьесбережения.

2. Учитывая, что здоровьесбережение включает процессы управления и регуляции разной степени осознанности, в то же время взять за основу положение о главенствующей роли целенаправленной деятельности субъекта по управлению здоровьем.
3. Опираться в исследовании здоровьесберегающей деятельности на современные методологические основания, соответствующие уровню сложности объекта, принципы системного и метасистемного подхода

Мы полагаем, что здоровьесберегающая деятельность как инструментальная по своему характеру не имеет собственных психологических средств ее реализации. Различные умения и навыки, усвоенные в процессе жизнедеятельности человека, свойства его личности могут либо свидетельствовать, либо не свидетельствовать об уровне здоровья в зависимости от того, насколько они интегрированы в систему здоровьесбережения и влияют на длительность и продуктивность жизни человека. Следовательно, не существует прямых личностных критериев здоровья, поиском которых длительное время занимались исследователи $[1,4,5,6]$. С другой стороны, в процессе здоровьесбережения личность использует уже имеющиеся у нее ресурсы и способности, которые сформировались в ходе содержательного освоения мира, объединяя их в принципиально новые метадеятельностные контуры [3].

Именно поэтому для исследования здоровьесберегающей деятельности мы предлагаем ис- 
пользовать конструкт компетентности, который позволяет исследовать свойства субъекта, включенные в структуру деятельности. Конструкт компетентности привлекает нас еще и потому, что в нем заложена системная социально-психологическая трактовка онтогенеза и актуалгенеза деятельности: ориентация на содержательный результат и формирование социально-значимого опыта деятельности. По определению В.Д. Шадрикова, компетентность - новообразование субъекта деятельности, представляющее собой системное проявление знаний, умений, способностей и личностных качеств, позволяющее успешно решать функциональные задачи, составляющие сущность деятельности [11]. Разработка категории компетентности в контексте метасистемной парадигмы представляется перспективной, так как она позволяет исследовать человеческую жизнедеятельность как систему освоения и созидания общественно-практического опыта [10]. В русле этой парадигмы компетентность в области здоровьесбережения есть компетентность второго порядка, поскольку ее отличительной особенностью является интеграция уже сформированных компетентностей личности в общий процесс обеспечения ее жизненной безопасности. В нашем исследовании она определена как витальная метакомпетентность личности, то есть компетентность в управлении собственным здоровьем.

Витальная метакомпетентность - не единственное образование психики, ответственное за обеспечение здоровья человека. Неосознаваемые (или мало осознаваемые) субъектом механизмы, такие как бессознательная регуляция состояния организма, интуитивный выбор стратегии реагирования в угрожающей ситуации часто играют значительную роль в обеспечении оптимальной жизнедеятельности. Однако наибольшей практической ценностью обладают исследования системы регуляции здоровья, которую способен целенаправленно изменять, корректировать и оптимизировать сам человек как субъект здоровьесбережения. Эта осознанная система регуляции здоровья и уровень ее индивидуального развития составляют смысловое ядро понятия витальной метакомпетентности.

Как базовое понятие исследования витальная метакомпетентность рассматривается нами в двух смыслах: в широком - как системное свойство личности воспроизводить себя в основных жизненных свойствах, в узком - как психическое образование, характеризующее уровень и качество здоровьесберегающей деятельности субъекта. $\mathrm{K}$ ее существенным особенностям относятся инструментальный характер (необходимость для обеспечения любого вида деятель- ности), субъектность (компетентность в воздействии субъекта на самого себя, реализация самосубъектного отношения) и интегративность (объединение системных свойств других психологических систем) [12].

Объектами исследования витальной метакомпетентности на общесистемном уровне выступают единицы, которые обладают качественной специфичностью целого и представляют собой его содержательную репрезентацию [3]. В событийном плане витальная метакомпетентность выступает как психологическая система освоения жизненных событий, связанных с угрозой здоровью. Наиболее точно отразить специфичность деятельности субъекта по освоению связанных с угрозой здоровью событий, на наш взгляд, позволяет использование в качестве единицы анализа витальной компетенции. Понятие компетенции является рабочим конструктом современной организационно-управленческой теории компетентности и понимается либо как способность личности эффективно решать отдельную задачу $[8,10]$, либо как базовая характеристика личности, позволяющая прогнозировать поведение человека в достаточном спектре профессиональных и жизненных ситуаций [7].

Исходя из этого, в интегрированном виде витальная компетенция может быть определена как способность личности эффективно решать задачу по преодолению проблемной жизненной ситуации, связанной с угрозой здоровью, и использовать приобретенный опыт при решении подобных задач в будущем. При таком подходе витальная метакомпетентность личности - это активная и целенаправленная реализации субъектом своих витальных компетенций в социально-психологическом пространстве личности.

Одно из наших эмпирических исследований в русле концепции витальной метакомпетентности было посвящено формированию витальной компетенции комплаенса у пациентов с сердечнососудистыми заболеваниями. Комплаенс сложный комплекс характеристик личности, определяющий эффективность взаимодействия с врачом во время лечения, который включает адекватное отношение к болезни, доверие врачу, точное следование медицинским предписаниям, эффективность коммуникации с врачом во время терапии. В качестве групп исследования были привлечены пациенты стационарного отделения, не относившиеся по своей профессии к специалистам медицинского профиля, и врачи, проходившие курс лечения в качестве пациентов с заболеванием сходной нозологии. В группе испытуемых-врачей был выявлен эффект псевдокомпетенции, который заключался в том, что больные-врачи оценивали комплаенс с 
лечащим врачом как удовлетворительный, но в то же время лишь формально его осваивали. Хороший контакт с лечащим врачом не формировал приверженность терапии. Такие пациенты позже других осознавали необходимость стационарного лечения, меньше следовали предписанной стратегии лечения. Мы объясняем этот эффект социальнопсихологическими факторами, прежде всего особенностями профессиональной идентификации врача в лечебном процессе и профессиональной деформацией личности. В другом исследовании, построенном на сравнении особенностей здоровьесберегающего поведения студентов медицинского и немедицинского профиля, был обнаружен эффект иного рода. Наблюдались группы студентов медицинского и педагогического вуза, принявшие решение бросить курить (при слабой степени никотиновой зависимости по тесту Фагерстрома). Имея системные и глубокие знания о негативном влиянии никотина на организм человека, этапах преодоления вредной привычки к курению, будущие врачи чаще диагностировали у себя признаки влияния никотина на здоровье и эффективнее контролировали свое состояние во время абстиненции; это создавало ситуативные предпосылки для формирования компетенции преодоления привычки к табакокурению. В результате сравнительного исследования эффективности здоровьесберегающего поведения в группах студентов было обнаружено, что доля успешно бросивших курить с первой попытки среди студентов медицинского вуза была статистически достоверно больше. Таким образом, социально-психологический контекст ситуации и специфика жизненного опыта значимо влияет на качество витальных компетенций личности.

Как единице анализа витальной метакомпетентности на общесистемном уровне витальной компетенции присущи следующие свойства:

- индивидуальное своеобразие, которое определяется уровнем здоровьесберегающей деятельности у данной личности;

- функциональная интегрированность процессов здоровьесбережения в структуре витальной компетенции;

- ситуационная заданность структуры витальной компетенции, отражающая особенности решаемой задачи в области здоровьесбережения;

- мера сформированности, которая характеризует эффективность здоровьесберегающей деятельности личности в сложившихся условиях жизни и оценивается на основании таких критериев как осознанность, адекватность ситуа- ции, значимость последствий выбора поведения для обеспечения оптимального качества жизни, социально-психологическая обусловленность, возможность воспроизведения.

На основании последнего из указанных критериев мы выделили следующие уровни сформированности витальной компетенции: базовый, повторяемый, стандартизованный, управляемый и оптимальный.

Базовый уровень связан с освоением жизненного события без опоры на сформированную витальную компетенцию и соответствующий синтез метапроцессов здоровьесбережения. У человека нет сформированных представлений в отношении анализа жизненной ситуации и приемов ее преодоления, либо они незначительны. Уровень успешности освоения жизненного события будет обусловлен исключительно спонтанной тактикой поведения. Следует учесть, что базовый уровень может иногда обеспечить высокое качество освоения единичного события, но повторяемости результатов в этом случае достичь очень трудно. Переход витальной компетенции на следующий уровень фиксируется, если при освоении жизненных событий одного плана появляется стереотип действий. Впрочем, диапазон проявлений витальной компетенции на повторяемом уровне крайне узок и специфичен. Опыт, приобретенный человеком при решении однотипных по специфике и уровню сложности жизненных задач не переносится на ситуации, значимо отличающиеся от пережитых. Стандартизованный уровень витальных компетенций характеризуется тем, что набор витальных компетенций становится достаточно большим, охватывающим основные сферы жизнедеятельности личности. Однако они плохо взаимосвязаны между собой - это, скорее, набор витальных компетенций, подходящих для разных жизненных ситуаций, нежели их система. Формирование целостной системы витальных компетенций приводит к качественно новому уровню управления человеком своим здоровьесбережением. На управляемом уровне сформированности витальных компетенций он не просто адекватно реагирует на возникающие проблемы со здоровьем, а может их прогнозировать и активно предупреждать. Оптимальный уровень сформированности системы витальных компетенций позволяет человеку не только успешно преодолевать жизненные трудности, но и постоянно совершенствовать свои витальные компетенции в процессе личностного саморазвития.

Результаты эмпирических исследований показывают, что в условно-здоровой выборке преобладают базовый, повторяемый, стандартизованный уровни витальных компетенций. В то время 
как управляемый и оптимальный уровни встречаются относительно редко. Не выявлено статистически значимой зависимости сформированности витальных компетенций от возраста испытуемых. Есть достоверное преобладание повторяемого уровня витальных компетенций у женщин и статистическая тенденция к преобладанию стандартизованного стиля у мужчин, что, на наш взгляд, является проявлением гендерных различий.

Особая роль витальной метакомпетентности проявляется в ситуации длительного нарушения здоровья, хронического заболевания, инвалидизации. В этих ситуациях уровень сформированности витальных компетенций, особенности их интеграции во многом определяют эффективность медицинского вмешательства. При исследовании витальной метакомпетентности пациентов с цереброваскулярными заболеваниями нами было обнаружено, что профиль и качество витальных компетенций пациентов с неустойчивым эффектом лечения имеет существенную деформацию в сравнении с группой пациентов, демонстрирующих устойчивый эффект лечения в течение трех и более лет. Деформация наблюдалась как в структуре витальных компетенций, так и в уровне их сформированности. Был обнаружен феномен неуравновешенной парциальности профиля витальных компетенций пациентов с неустойчивым эффектом лечения. Полученные данные были положены в основу разработки комплексной стратегии лечения больных с цереброваскулярными заболеваниями [2]. Таким образом, уровень сформированности витальных компетенций задает устойчивость результатов лечения, а, следовательно, фон общей жизненной реализации.

Обобщая опыт использования конструкта витальной метакомпетентности в психологических исследованиях здоровья, можно отметить следующее.

1. Общепсихологический и социальнопсихологический анализ проблематики здоровьесбережения и применение в качестве методологии принципов метасистемного подхода открывают возможности развития нового направления исследований - психологии здоровьесберегающей деятельности субъекта.

2. В качестве базового понятия теории здоровьесберегающей деятельности следует использовать конструкт витальной метакомпетентности. Витальная компетентность в широком смысле рассматривается как системное свойство личности воспроизводить себя в основных жизненных свойствах, а в узком - как психическое образование, характеризующее уровень и качество здоровьесберегающей деятельности субъекта.
3. Системными единицами витальной метакомпетентности выступают витальные компетенции, представляющие собой способности эффективно осваивать проблемные ситуации, связанные с угрозой здоровью, в социально-психологическом пространстве личности.

4. Изучение сформированности и качества интеграции системы витальных компетенций задает широкое поле прикладных психологических исследований здоровья.

Исследование осуществлено при финансовой поддержке Российского научного фонда; № проекта 16-18-10030

\section{ЛИТЕРАТУРА}

1. Ананьев В.А. Введение в психологию здоровья. СПб. : Изд-во БПА, 1998. - 148 с.

2. Зоткина М.Н., Жаднов В.А., Яковлева Н.В. Индивидуальные клинико-неврологические и личностные особенности развития хронических форм цереброваскулярных заболеваний // Личность в меняющемся мире: здоровье, адаптация, развитие. Электронный научный журнал. - 2013. - № 1. - С. 88-94

3. Карпов А.В. Психология сознания. - М. : РАО, 2011. -1088 c.

4. Куликов Л.В. Психогигиена личности. Вопросы психологической устойчивости и психопрофилактики: Учебное пособие. - СПб. : Питер, 2004. - 464 с.

5. Лакосина Н.Д., Ушаков Г.К. Медицинская психология. - М : Медицина, 1984. - 272 с.

6. Маслоу А. Мотивация и личность. - СПб. : Питер, 2008. - 352 c.

7. Спенсер Л.М., Спенсер С.М. Компетенции на работе. - М. : НIPРО, 2005. - 384 c

8. Тихомиров Ю.К. Теория компетенций. - М. : Юринформцентр, 2001. - 352 с.

9. Урванщев Л.П., Яковлева Н.В. Формирование психологической компетентности врача в процессе обучения в медицинском вузе // Психологический журнал. - 1995. - № 4. - С. 98107.

10. Хамел Г., Прахалад К.К. Конкурируя за будущее. Создание рынков завтрашнего дня. - М.: ОлимпБизнес, 2002. - 288 с.

11. Шадриков В.Д. Профессиональные способности. М.: Университетская книга, 2010. - 320 с.

12. Яковлева Н.В. Витальная метакомпетентность личности: теория и практика психологического исследования здоровья. - Рязань : РязГМУ, 2012. $285 \mathrm{c}$. 